\title{
Literature Circles Online: Practical Strategies For Creating A Reading Culture Using Technology
}

\author{
Barbara Combes \\ Lecturer \\ School of Computing \& Information Science \\ Edith Cowan University \\ Perth \\ AUSTRALIA
}

Providing opportunities and learning environments on-line where students are actively engaged and feel in control of their own learning experiences, encourages lifelong learning skills development such as independence. problem-solving and higher order thinking. Discrete on-line environments can also use the functionality of the technology to facilitate different learning styles and provide a 'safe' environment where students can explore and experiment before presenting their ideas to a larger audience. This paper considers current research and the importance of the fiction collection in the development of literacy outcomes for all students. It also examines an interactive on-line module that: incorporates the concept of literature or reading circles to promote reading; the development of higher order literacy skills and encourages the development of a reading culture. The on-line module was developed using a model that utilises an holistic approach to learning to create a seamless learning environment where students work within a structured framework that is designed to foster independent learning and teamwork.

\section{Introduction}

As we enter the twenty-first century, cash-poor schools are looking to minimise costs while maximising outputs. With telecommunications technologies becoming increasingly available in classrooms, educational institutions and systems across the globe are reinforcing their commitment to the belief that the use of technology as a means of education delivery has the potential to significantly enhance teaching strategies and resources currently available to schools (SOCCI, 2000). Hence, despite current research that indicates that resilient school library programs run by pro-active teacher librarians (TL) are erucial elements for the achievement of student learning outcomes (Hartzell, 2002, Todd, 2003), we have a situation where school libraries and TLs worldwide are under threat and severe cutbacks in funds for resources a reality. The fiction collection particularly, is often viewed as a luxury and a non-essential item of the library collection.

The role of the TL is also often misunderstood and most administrators and staff in schools overlook the potential of this underutilised human resource. While the achievement of student literacy outcomes is a priority across educational systems, reduced funding and staffing has meant that the TL's capacity to provide quality fietion resources and literature programs has been severely reduced. One way of redressing these imbalances is to use technology to provide a whole-school approach 
to literature promotion that encourages the development of an inclusive reading culture, while highlighting the importance of fiction, the library and the TL in the development of literacy outcomes for all students.

\section{Why read fiction? Establishing a rationale for a reading culture}

The importance of reading and the role of fiction in the ongoing development of strong literacy skills for children and young adults cannot be over-stated. Fiction resources for children and young adults can be defined as "works produced ostensibly to give these readers spontaneous pleasure, and not primarily to teach them" (Darton, 1982).

Why read fiction? Students can learn to read using reading sets, so why have an extensive and expensive fiction collection in a school library? Providing a strong rationale to answer these questions is one strategy TLs can utilise when justifying expenditure on fiction resources for the Library/Resource Centre. In the midst of the hype surrounding the Technological Revolution, the Internet and on-line curriculum; administrators and teachers don't seem to be making the connections between reading widely and across many formats with high levels of literacy development. There is also a growing misconception that all educational resources can be found on the Internet.

When challenged to justify expenditure on fiction resources and litcrature programs, TLs have traditionally put forward the following arguments:

- reading fiction develops a love of literature.

- students have opportunities to practice reading for pleasure.

- any reading is worthwhile.

These arguments are still valid. However, we also need to be more specific and place the role of fiction and reading firmly into the arena of educational pedagogy and the development of literacy outcomes for our students. Recent research does show that students who read often and widely, particularly fiction, are more successful academically than those who do not (OECD, 2002). When this reading habit is a part of the culture of the school, students' literacy skills have been shown to improve significantly and even overcome social disadvantage.

For students to be successful learners in the twenty-first century, they need to have good literacy skills. With the advent of the technological revolution and the information society, good literacy skills are now more important than ever before. We also recognise that the term literacy as it is currently being used, is more than reading and writing. It also incorporates the development of lifelong learning skills - being able to locate, evaluate, analyse, deconstruct and synthesise information (information literacy), mathematical literacy, media literacy, computer or technological literacy and visual literacy to name a few.

As TLs, encouraging students to develop a love of reading and a good reading habit is only part of the equation. On a general level, students who read widely are exposed to a variety of text forms, vocabulary, concepts, understandings and ideas. They are continually being challenged to: 
- practise and further develop their reading literacy skills (vocabulary, complex sentence and text structure).

- make meaning of their world through real and imaginary experiences (prediction, sequencing, deconstruction).

- develop higher order thinking skills (problem-solving, analysis and evaluation).

Fiction texts also provide students with opportunities to:

- encounter and relate personally to a range of vicarious experiences.

- extend their understanding of different cultures and ethnic groups.

- extend their knowledge of history.

- develop understandings about personal interactions, conflict resolution and individual growth.

- deconstruet text for greater and deeper understanding.

When considering or justifying fiction resources for the library collection, the TL needs to have a clear understanding of their importance in promoting the overall development of a range of literacy skills, and this fact should be clearly articulated in the Collection Development Policy for the Library and promoted as an outcome for all students across the school. Fiction resources should be actively promoted and wherever possible, integrated into curriculum programs to provide students with the opportunities to develop the skills and experiences listed above. A wide range of fiction resources, of varying depth and breadth and using different formats will ensure that all students have opportunities to achieve literacy outcomes.

Maurice Saxby succinctly summarises the argument.

If they [children] have not been exposed to exact and gracefiul language from early, childhood (fiom the cradle), and if they have not become saturated with exemplars of literaly usage, there is little hope that they will become fluent in composition and word processing. Story, along with informative prose, still remains the highroad to literacy, and the love of literature and research to the mastery of language (Saxbl, 1997, p. 386).

\section{Why go on-line?}

Once the TL has established the importance of the fiction collection as part of a whole-school approach to the ongoing development of literacy outcomes, why go on-line? Aren't traditional literature promotion methodologies enough to engage students'? Of course traditional approaches can and do engage students, but why not use the technology as an additional motivational tool, while incidentally teaching students technology skills in a relevant context'?

Interactive on-line learning can exploit emerging technologies to provide alternative learning experiences and resources, cater for diverse student learning styles and individual differences, and create a learning culture that integrates 
technology, information literacy and literacy outcomes across the school. Using constructivist principles (eg. Oliver, 2002), teachers can design creative on-line learning materials such as Web Quests (Dodge, 2001), micro-world simulations, and other immersive, flexible design approaches that leverage the power of telecommunications technologies and the on-line environment. These materials have the ability to engage students in open-ended, inquiry-based learning that also encourages interaction and teamwork as a major part of the learning process. Individual learning and motivational styles, such as those identified in the 4Mat System: Imaginative Learning; Analytic Learning; Common Sense Learning and Dynamic Learning (McCarthy, 2004), can also be built into on-line learning materials through the use of alternative pathways and activities (Combes and Ring, 2004).

While the Internet and telecommunications technologies are currently being heralded as the new way to learn, current research is critical of system initiatives that take a top-down approach to the integration of technology into the curriculum. These initiatives fail to address the local needs of students and teachers and program development often appears to revolve around fitting learning into the Internet rather than integrating the technology into learning (Lemke, 1988, Blurton, 1999).

Local support includes local knowledge of the school community, students and their needs; a knowledge of curriculum across all learning areas, curriculum initiatives for that particular education system and the types of resources available in that school/community to ensure an holistic learning experience that caters for all learning styles. The TL is in an ideal position to provide this support, both in terms of resource provision and in the design of seamless curriculum that embeds information literacy and literacy skills development.

Creating interactive on-line learning experiences that develop reading and literacy skills is a natural extension of the TL's literature promotion role. The on-line medium is available 24/7, so students can access the program in their own time and work at their own pace. The on-line environment allows teachers to scaffold the learning environment and provide students with a range of support documents in an unobtrusive manner. Students can use the Internet for guided research to explore new avenues of information. The on-line environment can also be used as a conduit to alert students and staff to a range of other resources available within the school that utilise different formats and thus cater for different learning styles. Students can obtain individualised feedback from their teacher via email and participate in on-line discussion groups with their peers. They can even reach out to other students around the world to compare viewpoints and discuss issues or work collaboratively in teams. The on-line environment also allows students to publish their work and share with others, either within the school community (intranet) or on the global stage (Internet). For some students just using the technology itself is a motivation.

Interactive on-line environments can provide students with opportunities to become independent, self-directed learners within a highly structured and scaffolded learning environment that can be dynamic and engaging, while realising student learning outcomes including reading and literacy. The research (Blurton, 1999, Means, 1998) has identified the need for someone at the local level to take on the vital role of ensuring that teachers have ongoing, 'grass roots support'. This is needed to support the development of collaborative teaching-learning environments where all resources, human and physical, are used in the design and creation of curriculum 
programs that integrate technology into the learning culture of the school. The TL has the overarching curriculum knowledge, the collaborative background, manages curriculum resources across the school and is ideally placed to be such a key person.

Extending the use of the on-line medium into literature promotion and the development of literacy skills across the school not only integrates technology into the curriculum, it also promotes and raises the profile of the library and highlights the integral role of the fiction collection in the literacy skills program. The collaborative functionality supported by the technology also allows all students and staff to participate in literature programs that foster a reading culture within the school.

\section{Value adding to the equation - The Library + On-line + Literature Circles}

Combining the methodology employed in literature circles with the functionality of the on-line learning environment allows TLs and teachers to create a powerful learning tool. Using literature circles to explore a range of texts provides students with a framework and structure for organised discussion. The particular model used for the on-line Literature Circes module referred to in this paper, was developed by the TL of a Senior College (post compulsory level schooling for students aged between 16 and 21 years) in Perth Western Australia over a period of eighteen months and utilised 4MAT Constructivist theory and WebQuest methodology as a pedagogical base (Sevenoaks, 2003). The 4MAT Constructivist Model of Learning (About Learning Inc, 2004 allows students to move through the learning experience at their own pace while recognising and incorporating different learning styles. The WebQuest methodology engages students and encourages the development of higher order thinking skills. WebQuests employ role play in realistic contexts and allow students to work through a sequenced learning experience with a specific goal in mind.

The on-line model developed by the TL is designed to promote a seamless and discrete learning environment that utilises an holistic approach to learning. It incorporates a range of support documents that embed the development of information literacy and literacy skills throughout the particular unit of study. A feature of this model is an open learning environment where students are expected to problem-solve and usually role play within a relevant scenario/context. The roles played by students are usually multi-faceted and set in real life contexts. Collaboration and teamwork between students and staff and using a range of assessment tasks that includes work in progress are also elements of the on-line model. In the case of the Literature Circles unit, the methodologies - 4MAT, WebQuest and Literature Circles - were all pedagogically aligned.

The three basic elements of literature circles; diversity, self-choice and student initiative (Danicls, 2002b), encourage students to take control of the learning situation. During literature circles students meet in small groups to discuss a single text. They are responsible for choosing the text, organising and recording their group meetings and reporting back to either the whole class or to the teacher. Placing the framework for the program into the on-line module further enhances this perception that the students are in control of the learning environment. They can choose to aceess support documents or to explore additional information available on the Internet or in the school library collection. They can email notes to other students in the circle in 
preparation for the discussion sessions or connect with the teacher for informal discussions dealing with assessment or issues raised during the circle. The on-line medium offers opportunities for students to expand their learning in a 'safe' environment, where a certain amount of anonymity is assured that makes risk taking casier. Students who are not confident even in small group discussions can develop self-esteem and build confidence as they develop their face-to-face communication skills during group meetings. (Helt, 2003). In this context, the on-line medium enhances a feature observed in the research - that literature circles can assist in the building of student self-esteem (Stringer et al, 2003) and provides a structured framework where students are encouraged to take risks and share their thoughts and ideas with others, thus creating a more inclusive learning environment (Peralta-Nash and Dutch, 2000). The on-line medium also provides students with opportunities and extra support if they wish to extend the circle beyond the class time, thus promoting a culture of culture of discussion and reading reference that moves beyond the classroom and into the wider school community (Simpson, 1994).

Litcrature circles also use of a variety of roles. The titles used for these roles can vary depending on the number of students in each circle and the age group). In the Literature Circles on-line module the roles employed were Facilitator, Analyst, Word Wizard, Researcher and Scribe. Role play is also a feature of WebQuests and allows students to practise and focus on a particular skills set. However, students don't generally have direct instruction on how to participate in discussion groups or the roles they acquire (Brown, 2000). Using the on-line module allows us to build in extra information, including templates students can use to carry out their roles. Students still have autonomy and may access or modify these templates to suit their needs as their understanding and confidence grows. While working through their roles students develop a variety of other skills including lifelong learning and information literacy skills. They develop better time management; they learn how to make notes, write summaries and reports; and they use vicarious experiences to make meaning and connections with personal experiences and community issues, while increasing their vocabulary and comprehension skills (Lin, 2004). Again, the on-line medium can be used to enhance the face-to-face discussions. Links to on-line dictionaries and thesauri, glossaries of literature terms and information about literature genres can all be embedded seamlessly within the module.

\section{Assessing Literature Circles - why do it?}

According to Daniels (2003) "literature circles must be assessed. At the same time, we realize that overly intrusive assessments [can] undermine the spontaneity and trust that small-group conversations require". While assessment is an important tool for teachers to gauge student learning, it is also an essential component of student learning. Students participate in a variety of assessment practices such as peer assessment, reflections and self-evaluation to develop higher order, metacognitive thinking skills. Assessment in the form of written responses to literature enables readers to synthesize information and to comprehend at higher levels (Cantrell, 2002). The on-line module allows students to publish their thoughts and share with others either via email or in a publications section. A variety of response ideas with supporting links and documentation may also be provided. In this module students were given a selection of suggested activities such as writing a letter, creating a poster, designing a web page, writing song lyrics or a poem, drawing a cartoon, 
creating a picture book or photographic display and creating a problem-solving board game. Assessment responses such as these add interest and variety, as well as introducing creativity and challenge. Teachers can also monitor discussions, collect meeting schedules and checklists, as well as portfolios from each circle. Rubrics for assessment tasks, templates and instructions can also be readily accessed by students, so they know what is expected at all times. The on-line module may also become a vehicle for publication and showcasing student achievement.

\section{Who's in charge?}

The on-line literature circles module was not used to take the place of the teacher who is an essential component in the open learning environment. Indeed current research at the College indicates that while students are enjoying the flexibility provided by the on-line environment, they still insist that the teacher/facilitator is an essential component (Combes and Sekulla, 2003). The module was used to reinforce and support student learning, promote asynchronous discussion, assist students to develop effective management skills and provide opportunities to publish and share their thoughts with others across the College. Through the on-line medium and the literature circles, the students were helping to create a shared reading culture that extended beyond their particular classroom to the whole school.

\section{Flights of fantasy or core business? Literature promotion on-line}

Literature circles is a well researched methodology for engaging students in the reading, discussion and deconstruction of texts (Daniels, 2002a). Using literature circles in the classroom has resulted in demonstrated increases in student reading and comprehension levels, while fostering deeper thinking skills, and the analysis of issues and the structure of literary texts. Literature circles have also been found to promote a more inclusive classroom and reading culture. The combination of this methodology with technology provides opportunities for students to explore issues more widely, communicate easily with other group members and teachers, publish and showcase their work on-line and access a range of related texts in different formats.

For teachers and TLs, the on-line component provides a vehicle where student learning can be highly structured and supported in a seamless, unobtrusive manner. The on-line medium expands on the three main elements of literature circles diversity, self-choice and student initiative. Students are still in control of their own learning, while the teachers become facilitators, models and sometimes, active participants in literature circle discussions. In this way the staff became active participants in the inclusive reading community fostered by the use of literature circles. An important feature of the on-line environment is the collaborative functionality offered by the Web, which allows a whole school community to be involved in the development a reading culture. The on-line component offers another dimension to literacy skills development that allows us to integrate technology into learning rather than fitting learning into technology. Promoting literature on-line also raises the profile of the Library, the fiction collection and the role of the TL in the development of literacy skills across the school. 


\section{References}

About Learning Inc. (2004) [on-line] Retrieved from http:/www.aboutlearning.com/

Blurton. C (1999). World Communication and Information Report, UNESCO. [on-line] Retrieved from http://www.uncsco.org/education/educprog/wf/dl/edict.pdf

Brown. Barbara Ann. (2000). Literature Circles in action in the Middle School Classroom, ER/C Digest.

Cantrell, Susan Chambers. (2002). Promoting talk: A framework for reading discussions in teacher education courses, Journal of Adoleseent \& Adult Literacy, 45 (7) $642-651$.

Chatel, Regina G. (2003) Developing literacy in the technological age: Expanding the boundaries of reader-text interactions, The New England Recading Association. Journal, 39 (2) 67-73.

Combes, B and Ring, J. (2004). "If you help us huild it. We will come!" - The role of the Teacher. Librarian as an on-line curriculum fecilitator and immovator. Virtual paper presented at the ASLA On-line 1: Constructing Communities of Learning and Literacy On-line Conference. May 2004.

Combes, B. and Sekulla, G. (2003) Education in Cyberspace: Creating On-line Curriculum Through Effective Partnerships, the International Journal of Learning, 10.

Darton, F.J.H (1982). Children's Books in England: Five Centuries of Social Life (3rd Ed.) Rev. by Brian Alderson, Cambridge: Cambridge University Press.

Danicls. H. (2002a). But does it work? Recent rescarch on literature circles, Literature Circles.com. Retrievded from http://www.literaturecircles.com/research.htm

Daniels, H. (2002b). Literature Circles: Voice and Choice in Book Cluhs and Reading Groups (2nd ed.). Portland, ME: Stenhouse.

Daniels, Harvey. (2003). How can you grade Literature Circles? loices from the Middle 11 (1).

Hartzell, G. (2002). Why Should Principals Support School Libraries? FRIC Digest. Retrieved from ERIC Digest, http://ericit.org/digests/EDO-IR-2002-(06.shtml

Helt, Melanie. (2003). Writing the Book on On-line Literature Circles, Learning and Le'ading with Technology 30 (7) 28-31.

Lemke, C. (1998). Taking Stock: What Does the Research Say About Technology's Impact on Education? Interview with Cheryl Lemke. Technology \& Leaming. [on-line] Retrieved from http:/www.techlearning.com/db_area/archives/TL/062000/archives/lemke.html

Long, Trisha Wies and Gove. Mary K. (20043/4). How engagement strategies and literature circles promote critical response in a fourth-grade, urban classroom. The Reading Teacher, 57 (4)

Lin, Chia-Hui. (2004). Elements of Literature Cireles, Teacher Lihrariam, 31 (3) 23-25.

Means, B. (1998). Taking Stock: What Does the Research Say About Technology's Impact on Education? Interview with Barbara Means. Technologl' \& Learming. [on-line] Retrieved from http:/www.techlcarning.com/db area/archives/TL/062000/archives/barbara.html

OECD. (2002). Reading for Change: Performance and Engagement across Countries: Results from PISA 2000, [on-line]. Available: http://www.pisa.oced.org/Docs/Download/reading_for_change.pdf

Oliver. R. (2003). Learning designs supporting quality on-line learning experiences. In Partmers in Learning. Proceedings of the 12th Annual Teaching Leaming Forum, 11-12 February 2003

Peralta-Nash, Claudia and Dutch, J. A. (2000). Literature circles: Creating an environment for choice, Primery Voices $K-6,8(4)$

Saxby, Maurice. (1997). Books in the Life of a Child: Building Bridges to Literature and Learning. South Yarra: Macmillan.

Schools On-line Curriculum Content Initiative (SOCCI). (2000). Delivering the promise. The Le(a)rning Federation. [on-line] Retrieved from http://www. thelearningfiederation.edu.au/repo/cms2/published/3295/docs/trinitas.pdf

Sevenoaks Senior College. (2003). Snapshots of Online Curriculum. [online] Retrieved from http://www.sevenoaks.wa.edu.au/linkpage/index.html

Simpson. Ann. (1994). Not the class novel: A different reading program, Jommal of Adolescent and Adult Literacy, 38 (4) 290-294.

Stringer, S. at al. (2003). Collaboration between classroom teachers and a school counselor through literature circles: Building self-esteem, Journal of Instructional Psychology. 30 (1).

Todd, R. (2003). School libraris: Making them a class act. Paper presented at the 2003 WASLA Conference. [on-line] Retrieved from http:/scils.rutgers.edu/-rtodd/ 
Author Note:

Barbara has recently taken up a position at Edith Cowan University where she is lecturing for the School of Computing and Information Science (SCIS). During 2001-2002 she worked as the Teacher Librarian and Information Manager at Sevenoaks Senior College. In this role Barbara managed the Library and Information Centre, acted as webmaster for the College and was the WebCT and HarvestRoad Administrator. Another aspect of her role has involved working closely with staff on the development of a range of online curriculum modules and online courses to support teaching-learning programs at the College. She can be contacted at b.combes@ecu.edu.au 